ORIGINAL ARTICLE

\title{
Skin capacitance mapping of psoriasis
}

\author{
E Xhauflaire-Uhoda, C Piérard-Franchimont, GE Piérard* \\ Department of Dermatopathology, University Hospital Sart Tilman, Liège, Belgium
}

\author{
Keywords \\ capacitance, psoriasis, silicon image sensor \\ technology, stratum corneum \\ ${ }^{*}$ Corresponding author, Department of \\ Dermatopathology, CHU Sart Tilman, B-4000 \\ Liège, Belgium, tel. +32 43662408; \\ fax +32 43662976; \\ E-mail: gerald.pierard@ulg.ac.be \\ Received: 26 August 2005, \\ accepted 14 December 2005 \\ DOI: 10.1111/j.1468-3083.2006.01787.x
}

\begin{abstract}
Background The pathobiological dynamics of psoriatic lesions are complex and difficult to perceive by clinical inspection alone. Non-invasive bioengineering methods may prove to be useful in this field.

Objective To identify some subtle capacitance variations in the stratum corneum of chronic psoriasis lesions.

Method The newly developed method of skin capacitance imaging was used to provide non-optical images of the hydration of the superficial layers of the stratum corneum.

Results Compared to the uninvolved skin, psoriatic lesions usually showed an overall lowered capacitance, admixed with foci of moderately higher capacitance. Still other sharply circumscribed blotches with higher capacitance were present. The latter aspect corresponded to inflammatory areas. Sweating appeared markedly impaired inside the lesions. The fingerprint of some patients was altered, thus potentially interfering with the current biometric security procedures using the same method.

Conclusion Skin capacitance imaging is a non-invasive, non-optical method that distinguishes three contrasting levels of stratum corneum hydration in psoriatic lesions. The lowest capacitance level probably corresponded to xerotic orthokeratosis. The medium capacitance level presumably identified foci of parakeratosis and clumps of neutrophils. The highest capacitance level suggested exsudation the site of prominent vessel dilation and dermal inflammation. Impaired sweating in the psoriatic lesions may potentially interfere with body thermoregulation.
\end{abstract}

\section{Introduction}

Psoriasis is a chronic, immuno-inflammatory disorder that is characterized by keratinocyte hyperproliferation, abnormal keratinocyte differentiation and dermo-epidermal inflammatory infiltration. ${ }^{1}$ The clinical and histological presentations may vary according to the type and body location of the lesions. ${ }^{2}$ The psoriasis area and severity index (PASI) is considered to be an appropriate means of evaluating the severity of plaque-type psoriasis. ${ }^{3,4}$ However, in some conditions, PASI may be considered as only a gross evaluation, calling for more detailed information. Indeed, the reliability of the visual grading method that is most commonly used in this scoring system is relatively poor. ${ }^{5-7}$ Marked variations exist between the estimates of clinicians, thus impeding the scoring reproducibility. Objective and quantitative approaches have been developed to improve the validity of the PASI scoring system. ${ }^{6-8}$ Long-term prognostic factors other than the PASI score have been identified. ${ }^{9}$ New assessment methods are welcome because the current and upcoming treatments offer new opportunities, ${ }^{4,10}$ but also create the problem of objective and specific assessment of psoriasis evolution.

Psoriatic lesions are far less uniform in their histological structure than the uninvolved surrounding skin. ${ }^{11}$ The density of the inflammatory infiltrate, the vasculature hyperplasia, the epidermal thickening, and the extent of hyper- and parakeratosis may indeed show large interindividual and intra-individual variations. ${ }^{4,11,12}$ The clinical examination may detect some of the variations, but 
dermoscopy and a few specific non-invasive bioengineering methods may help in identifying them with increasing specificity and sensitivity. ${ }^{13,14}$ The same methods can help in assessing the benefits and side-effects of antipsoriatic therapies. ${ }^{14}$

Any change in the structure of the stratum corneum is potentially associated with alterations of both barrier function and water holding capacity. ${ }^{15,16}$ These changes affect the electrical properties of the skin. ${ }^{17-19}$ Recently, a novel method of skin capacitance mapping was developed, showing for the first time detailed differences in hydration of the stratum corneum over the skin surface. ${ }^{20-23}$ Skin capacitance mapping is based on silicon image sensor (SIS) technology, initially developed for sensing fingerprints in biometric security procedures. This method has already been used to explore a variety of physiopathological conditions. $^{24-31}$

The aim of the present study was to perform skin capacitance mapping of chronic psoriatic lesions and fingerprints in the same patients.

\section{Patients and method}

Psoriatic plaques and fingerprints were examined in 20 adult patients using the SkinChip $®$ device (L'Oréal, Paris, France). A total of 92160 capacitance measurements distributed every $50 \mu \mathrm{m}$ are collected over the $18 \times 12$, 8 mm sensor probe. ${ }^{20-23}$ The device was closely applied to the skin surface for a maximum of $5 \mathrm{~s}$ in order not to interfere with the water flux and content inside the stratum corneum. ${ }^{30}$ The measurements were acquired in real time and displayed on a computer screen where the capacitance values were transformed into a range of 256 grey levels to form a non-optical image. The great variety of skin surface patterns of hydration and topography can be viewed on these non-optical images. The darker pixels represent hydrated high capacitance spots. Clear pixels may represent dry spots of the skin or depressions and lines in the skin's microrelief, impeding the contact between the probe and the stratum corneum. ${ }^{20,21}$

\section{Results}

The criss-cross pattern of the primary and secondary lines of the skin microtopography was clearly identified outside the psoriatic lesions (fig. 1). This aspect was blurred inside the psoriatic lesions, which were characterized by an overall whitish aspect (fig. 1). This low conductance presentation was not uniform, but rather formed different pin-point, reticular or cobbled patterns (fig. 2). The whiter areas were not sharply circumscribed, and their borders merged with foci of moderately higher capacitance (fig. 2). In some instances, the low capacitance area was contiguous

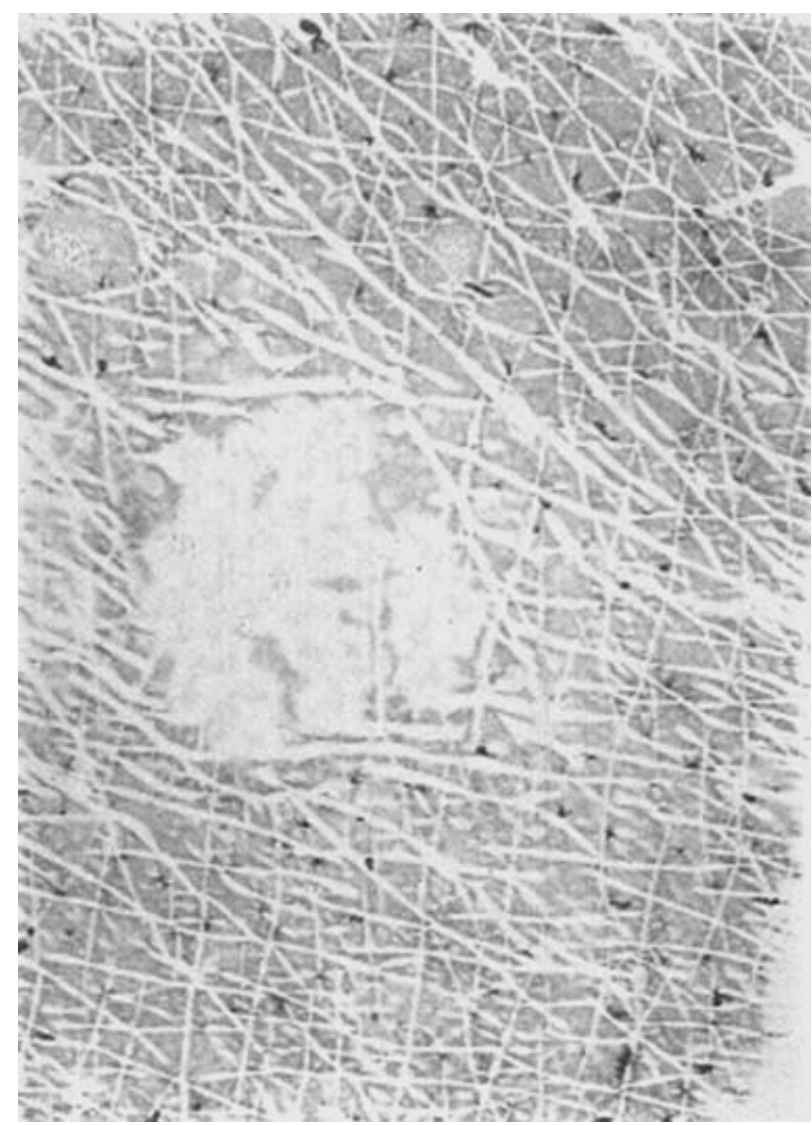

fig. 1 Skin capacitance imaging of a small lesion of psoriasis. The lesion exhibits lower capacitance (whitish aspect) with loss of the criss-cross pattern of skin lines seen in the surrounding normal skin. The darker spots in the peripheral skin represent the opening of active acrosyringia.

to a contrasting, sharply circumscribed, high capacitance area (fig. 3). The latter aspect often corresponded to a more erythematous area.

Active sweat pores were recognized by pin-point darker (high conductance) spots. They were almost always absent inside the psoriatic lesions, although they were identified in the surrounding skin (figs 1 and 4).

The fingerprint pattern was obscured by the low capacitance aspect of minute hyerkeratotic lesions, presumably corresponding to psoriatic manifestations (fig. 5).

\section{Discussion}

The present findings suggest a contrasting 3-level capacitance of the stratum corneum in psoriatic lesions. The vast proportion of the whitish areas represented low capacitance structures in the stratum corneum. They probably corresponded to xerotic hyperkeratotic areas. These dryer areas formed different patterns of arrangements, merging with other areas showing a medium level capacitance. These 


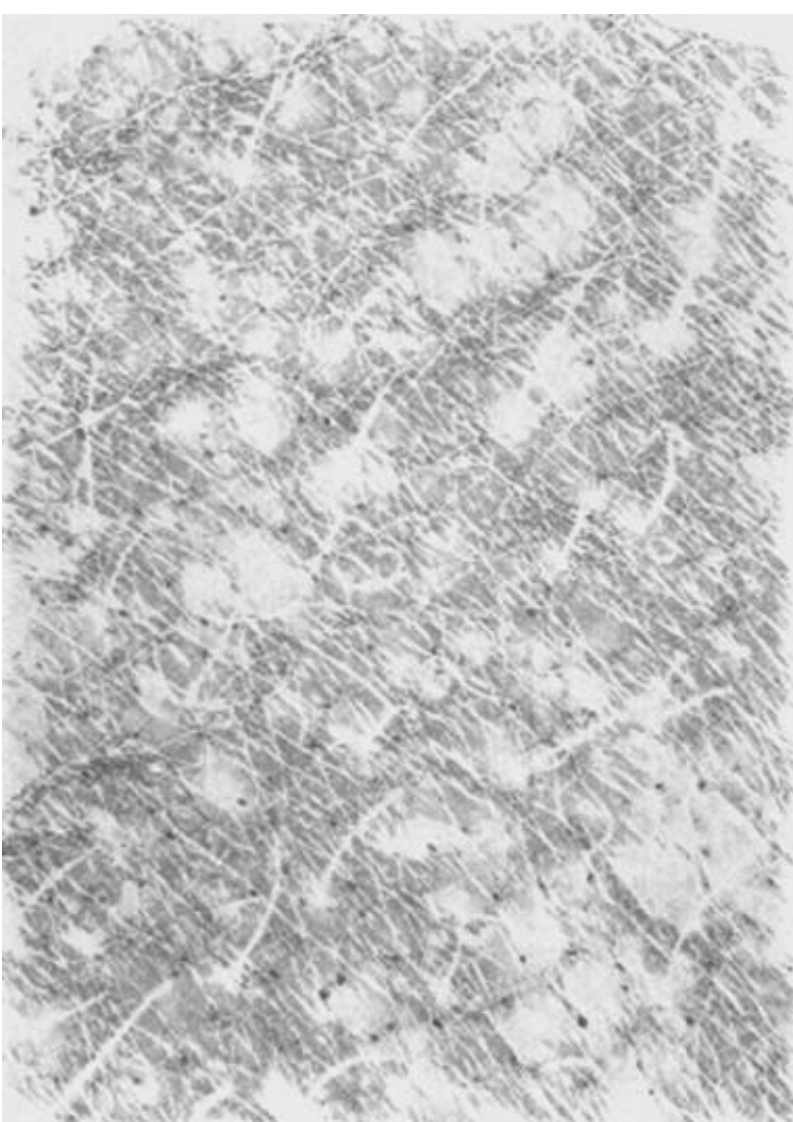

fig. 2 Cobbled pattern of low capacitance blotches admixed with medium level capacitance inside a psoriatic plaque.

latter areas were tentatively interpreted as parakeratotic foci admixed with neutrophils. Indeed, these epidermal and inflammatory cells are presumably more hydrated than the corneocytes cuffing the hyperkeratotic layer. In addition, psoriatic lesions showed other areas exhibiting a third level of much higher capacitance. These foci were sharply circumscribed and corresponded to an erythematous aspect of the lesions. Whether these areas corresponded to the site of superficial vascular hyperplasia and dilation and/or to more severe inflammation has not been determined. Whatever the case, the high capacitance may result from serum leakage from the microvasculature, finally steeping the stratum corneum. This aspect suggests active pathogenic mechanisms of psoriasis.

Sweating appeared particularly impeded within psoriatic lesions. The same observation has previously been described in lesions of pityriasis versicolor. ${ }^{28}$ It is possible that the process of sweat excretion at the opening of the acrosyringia is notably altered in cases of xerosis. This event may modify thermoregulation, $\mathrm{pH}$ regulation of the skin surface and any molecular contribution of sweat to the biology of the stratum corneum. ${ }^{28}$

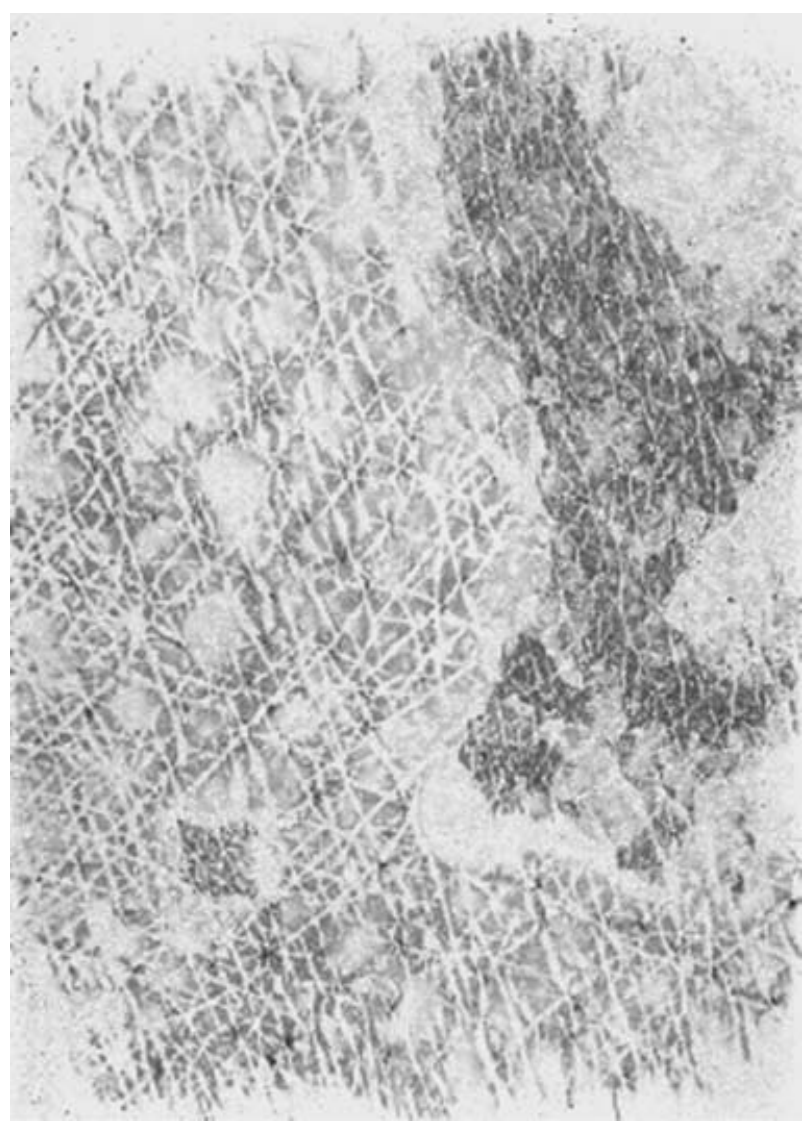

fig. 3 Capacitance mapping of a psoriatic lesion similar to that depicted in fig. 2. In addition, a sharply circumscribed darker area of higher capacitance is present corresponding to an inflammatory area.

Dermatoglyphics have been reported to show particular patterns in psoriatic patients. ${ }^{32}$ The Skinchip ${ }^{\circledR}$ device could be used to study these aspects. ${ }^{20,21,28}$ The present study was not designed for that purpose. However, our observations showed minute involvement of the digit pulp by psoriasis. Irregularly shaped, low capacitance networks were shown, indicating discrete hyperkeratosis blurring the dermatoglyphics.

In conclusion, non-optical skin capacitance imaging revealed some heterogeneity in the quality and physical properties of the stratum corneum in psoriatic lesions. Three main distinct levels of capacitance were revealed, each of them probably corresponding to structural and functional differences in the pathobiology of psoriasis. Skin capacitance imaging could be used to monitor the evolution of psoriasis in a rapid and non-invasive way. The effects of treatments on these physical characteristics are yet undetermined. The method is not a diagnostic tool, but rather shows some physiopathological and functional features that may be similar in different dermatoses. 


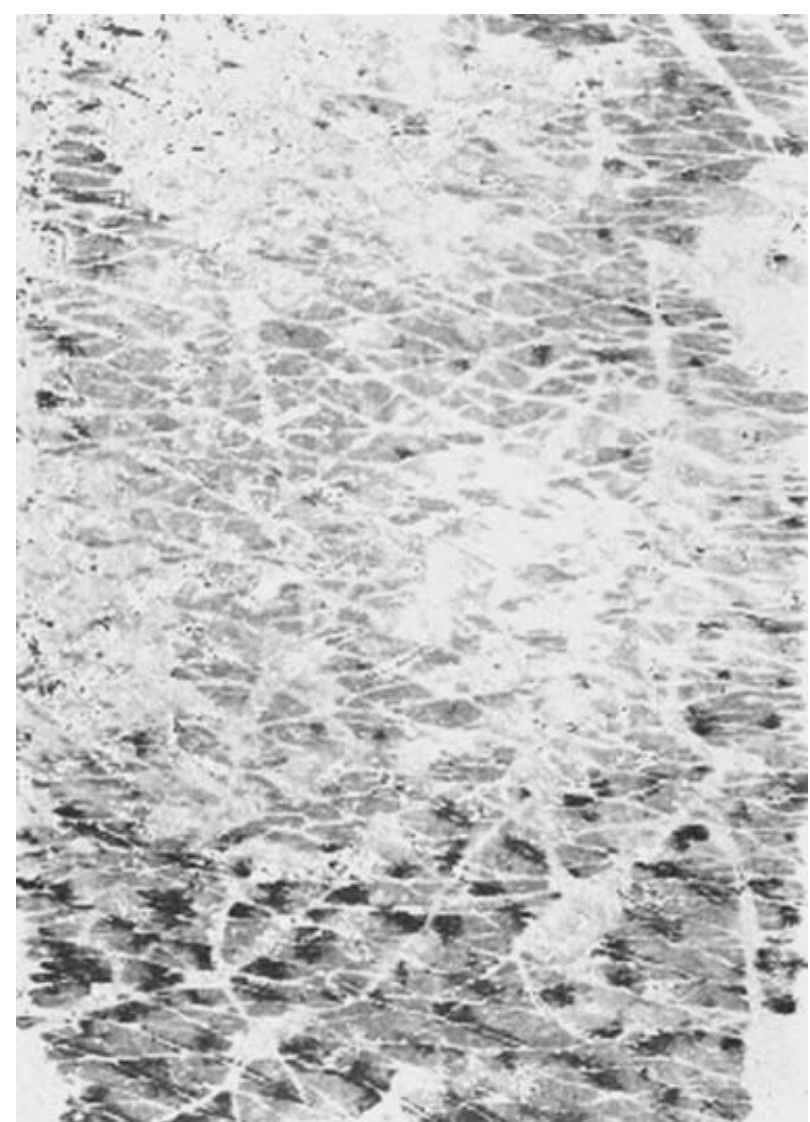

fig. 4 Intense sweat gland activity outside a psoriatic lesion.

\section{Acknowledgements}

We are grateful to Mr JL Lévêque (L'Oréal, Paris) who provided us with the Skinchip® device.

\section{References}

1 Prinz JC. The role of T cells in psoriasis. J Eur Acad Dermatol Venereol 2003; 17: 257-270.

2 Vissers WHPM, Roelofzen J, De Jong EMGJ, Van Erp PEJ, Van de Kerkhof PCM. Flexural versus plaque lesions in psoriasis: an immunohistochemical differentiation. Eur J Dermatol 2005; 15: 13-17.

3 Schmitt J, Wozel G. The psoriasis area and severity index is the adequate criterion to define severity in chronic plaque-type psoriasis. Dermatology 2005; 210: 194-199.

4 Julien D, Prinz JC, Langley RGB et al. T-cell modulation for the treatment of chronic plaque psoriasis with efalizumab (Raptiva $\left.{ }^{8}\right)$ : mechanisms of action. Dermatology 2004; 207: 297-306.

5 Marks R, Barton SP, Shuttleworth D, Finlay AY. Assessment of disease progress in psoriasis. Arch Dermatol 1989; 125: 235-240.

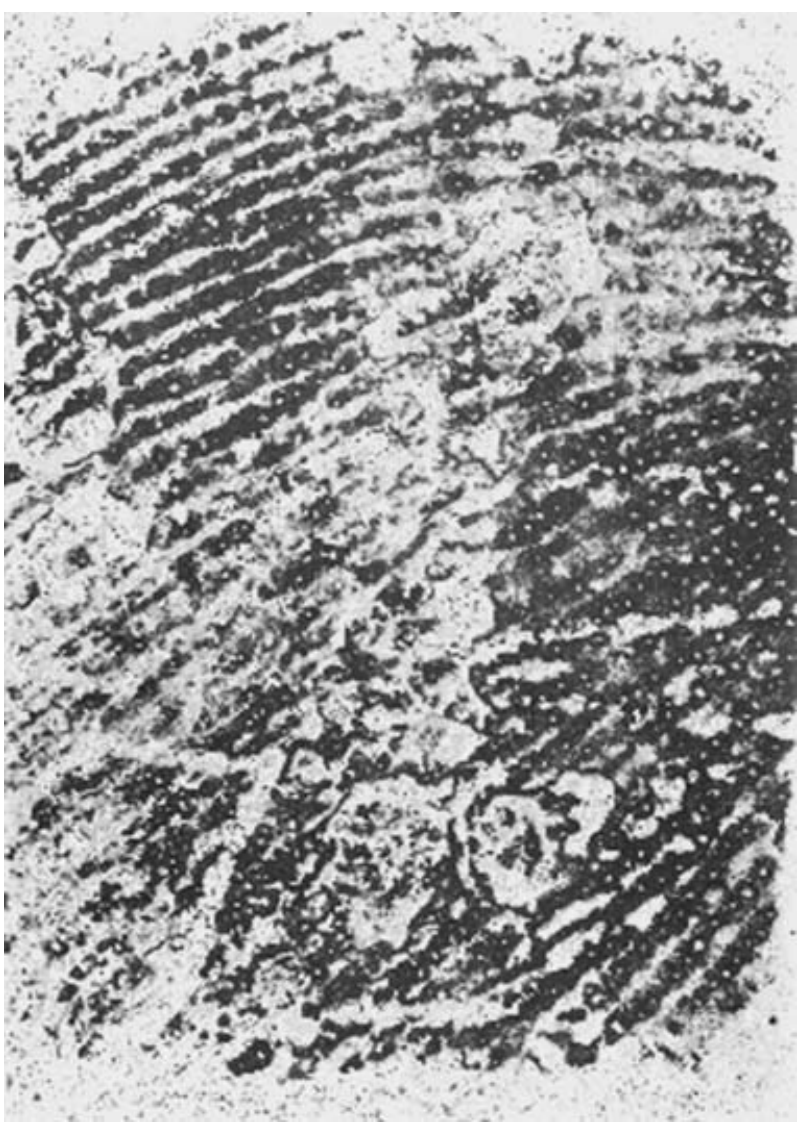

fig. 5 Alteration of the fingerprint of a psoriatic patient due to the presence of minute spots of hyperkeratosis.

6 Ramsay B, Lawrence CM. Measurement of involved surface area in patients with psoriasis. Br J Dermatol 1991; 124: $565-570$.

7 Tiling-Grosse S, Rees J. Assessment of area of involvement in skin disease: a study using schematic figure outlines. Br J Dermatol 1993; 128: 69-74.

8 Yune YM, Park SY, Oh HS et al. Objective assessment of involved surface area in patients with psoriasis. Skin Res Technol 2003; 9: 339-342.

9 Sakai R, Matsui S, Fukushima M, Hasuda H, Miyauchi H, Miyachi Y. Prognostic factor analysis for plaque psoriasis. Dermatology 2005; 211: 103-106.

10 Naldi L. A new era in the management of psoriasis? Promises and facts. Dermatol 2005; 210: 179-181.

11 Ragaz A, Ackerman AB. Evolution, maturation, and regression of lesions of psoriasis. New observations and correlation of clinical and histologic findings. Am J Dermatopathol 1979; 1: 199-214.

12 Uhoda I, Piérard GE, Piérard-Franchimont C et al. Vascularity and fractal dimensions of the dermo-epidermal interface in guttate and plaque type psoriasis. Dermatology 2005; 210: 189-193. 
13 Vasquez-Lopez F, Manjon-Haces JA, Maldonado-Seral C, Raya-Aguado C, Perez-Oliva N, Marghoob AA. Dermoscopic features of plaque psoriasis and lichen planus: new observations. Dermatology 2003; 207: 151-156.

14 Stücker M, Hoffmann M, Altmeyer P. Instrumental evaluation of retinoid-induced skin irritation. Skin Res Technol 2002; 8: 133-140.

15 Bouwstra JA, de Graaff A, Gooris GS, Nijsse J, Wiechers JW, van Aelst AC. Water distribution and related morphology in human stratum corneum at different hydration levels. $J$ Invest Dermatol 2003; 120: 750-758.

16 Rawlings AV, Matts PJ. Stratum corneum moisturization at the molecular level: an update in relation to the dry skin cycle. J Invest Dermatol 2005; 124: 1099-1110.

17 Berardesca E. EEMCO guidance for the assessment of stratum corneum hydration: electrical methods. Skin Res Technol 1997; 3: 126-132.

18 Fluhr JW, Gloor M, Lazzerini S, Kleesz P, Grieshaber R, Berardesca E. Comparative study of five instruments measuring stratum corneum hydration (Corneometer CM 820 and CM 825, Skicon 200, Nova DPM 9003, DermaLab). Part I. In vitro. Skin Res Technol 1999; 5: 161-170.

19 Fluhr JW, Gloor M, Lazzerini S, Kleesz P, Grieshaber R, Berardesca E. Comparative study of five instruments measuring stratum corneum hydration (Corneometer CM 820 and CM 825, Skicon 200, Nova DPM 9003, DermaLab). Part II. In vitro. Skin Res Technol 1999; 5: 171-178.

20 Lévêque JL, Querleux B. SkinChip®, a new tool for investigating the skin surface in vivo. Skin Res Technol 2003; 9: 343-347.

21 Piérard GE, Lévêque JL. What is SkinChip®? From silicon image sensor technology to SkinChip ${ }^{\circledR}$. Dermatology 2004; 208: 291-292.
22 Lévêque JL. Étude de la surface cutanée par Skinchip. In: Uhoda E, Paye M, Piérard GE, eds. Actualités en Ingénierie Cutanée, Vol. 4. Eska, Paris, 2006: 225-231.

23 Batisse D, Giron F, Lévêque JL. Capacitance imaging of the skin surface. Skin Res Technol 2006; 12: 99-104.

24 Piérard GE, Uhoda I, Piérard-Franchimont C. From skin microrelief to wrinkles: an area ripe for investigation. $J$ Cosmet Dermatol 2003; 2: 21-28.

25 Lévêque JL, Goubanova E. Influence of age on lips and the perioral skin. Dermatology 2004; 208: 307-313.

26 Uhoda E, Lévêque JL, Piérard GE. Silicon image sensor technology for in vivo detection of surfactant induced corneocyte swelling and drying. Dermatology 2005; 250: 184-188.

27 Uhoda E, Piérard-Franchimont C, Petit L, Piérard GE. The conundrum of skin pores in dermocosmetology. Dermatology 2005; 210: 3-7.

28 Uhoda E, Piérard-Franchimont C, Piérard GE. Pityriasis versicolor anhidrotique. Dermatol Actual 2005; 89: 16-17.

29 Xhauflaire-Uhoda E, Loussouarn G, Haubrechts C, Saint Léger D, Piérard GE. Skin capacitance imaging and corneosurfametry. A comparative assessment of the impact of surfactants on stratum corneum. Contact Dermatitis 2006; 54: 249-253.

30 Xhauflaire-Uhoda E, Piérard GE. Skin capacitance imaging of acne lesions. Skin Res Technol; in press.

31 Xhauflaire-Uhoda E, Piérard-Franchimont C, Piérard GE. Contrasted skin capacitance imaging of seborrheic keratoses and melanocytic naevi. Dermatology 2006; 212: 394-397.

32 Pour-Jafari H, Farhud DD, Yazdani A, Chaleshtori MH. Dermatoglyphics in patients with eczema, psoriasis and alopecia areata. Skin Res Technol 2003; 9: 240-244. 